\title{
Subtyping of Neisseria gonorrhoeae auxotype-serovar groups by pulsed-field gel electrophoresis
}

\author{
C. L. POH and O. C. LAU
}

Department of Microbiology, Faculty of Medicine, National University of Singapore, Lower Kent Ridge Road, Singapore 0511

\begin{abstract}
Summary. Genomic DNA from 48 Neisseria gonorrhoeae isolates was digested with lowfrequency cleavage (LFC) endonucleases (SpeI and NheI) and analysed by contour-clamped homogeneous electric fields electrophoresis (CHEF). The restriction patterns generated were reproducible, stable, easy to read and offer a more practical approach than restriction endonuclease analysis (REA) with high-frequency cleavage (HFC) endonucleases. Strains sharing common auxotypes and serovars could be differentiated and correlation with auxotype/serovar (A/S) classes was demonstrated for some, but not all strains. The strains were distributed into $18 \mathrm{~A} / \mathrm{S}$ classes and $38 \mathrm{SpeI}$ and $40 \mathrm{NheI}$ restriction patterns. This greater discriminatory power of CHEF REA should allow subdivision of strains within common A/S classes.
\end{abstract}

\section{Introduction}

The use of various typing schemes has greatly facilitated understanding of the molecular epidemiology of Neisseria gonorrhoeae. ${ }^{1}$ Serotyping with monoclonal antibodies (MAbs) has allowed greater differentiation of strains than either auxotyping or plasmid-profile analysis. ${ }^{2}$ However, serotyping has two major limitations; new MAbs have to be developed continually to type strains not covered by the existing panel and more discrimination is required within major serovars such as IB-1 and IB-3. ${ }^{3}$ Some strains react with only one MAb and if these strains were to mutate, they would no longer be typeable. ${ }^{4}$ Other problems include the long-term availability of MABs, batch-to-batch reagent variation and the reproducibility of co-agglutination reactions, especially with MAbs 2D6, 2G2 and 6D9.5 The auxotypeserovar (A/S) classification system is currently the most widely accepted method for typing $N$. gonorrhoeae despite the inherent limitations of its component systems.

In restriction endonuclease digest analysis (REA) resolved by conventional polyacrylamide ${ }^{6}$ or agarose $\mathrm{gel}^{2}$ electrophoresis, no strong correlation was found between REA patterns and serovar classification. However, REA often produces complex patterns that are difficult to interpret. Other variables affecting REA patterns are the choice of restriction endonucleases used and the electrophoresis systems employed.

Genotypic characterisation of strains by pulsedfield gel electrophoresis (PFGE) has been found to be useful for analysis of patterns generated by restriction

Received 18 June 1992; revised version accepted 8 Oct. 1992 enzymes that cut chromosomal DNA infrequently. ${ }^{8} \mathrm{~A}$ small number of high-mol.-wt DNA fragments are produced, giving simple, readily interpretable patterns. Furthermore, electrophoresis conditions can be adjusted to resolve fragments over a wide range of molecular sizes, enabling the whole genome to be analysed on a single gel. PFGE has been found to be highly discriminatory in studies of Candida albicans, ${ }^{9}$ Pseudomonas aeruginosa, ${ }^{10}$ Staphylococcus aureus, ${ }^{11}$ Campylobacter jejuni ${ }^{12}$ and Escherichia coli. ${ }^{13}$

This study describes the application of PFGE for typing of $N$. gonorrhoeae in comparison with $\mathrm{A} / \mathrm{S}$ typing.

\section{Materials and methods}

\section{Bacterial strains and culture conditions}

Forty-eight clinical isolates of $N$.gonorrhoeae (table) were grown on modified Thayer-Martin Agar (MTM; BBL) and incubated at $37^{\circ} \mathrm{C}$ in $\mathrm{CO}_{2}$ humidified air with $\mathrm{CO}_{2} 5 \%$ for $20 \mathrm{~h}$.

\section{Serological characterisation}

Strains were serotyped by S. Sarafian and J. Knapp, Centers for Disease Control, Atlanta, GA, USA, with six MAbs specific for protein IA (PrIA) and six specific for protein IB (PrIB).

\section{Genomic DNA preparation}

Fresh overnight cultures were harvested, washed with PIV solution (10 mM Tris- $\mathrm{HCl}, \mathrm{pH} 7.5,1 \mathrm{M}$ $\mathrm{NaCl}$ ), resuspended in $2 \mathrm{ml}$ of PIV, mixed with $2 \mathrm{ml}$ of low-melting point agarose (Sea Plaque LMP; FMC Corp., Marine Colloids Div., Rockland, ME, USA) 
Table. Phenotypic characteristics of $N$. gonorrhoeae strains used in this study

\begin{tabular}{|c|c|c|c|}
\hline Strain no. & Auxotype & Serovar & Fig./Lane \\
\hline 1 & Pro $^{-}$ & IB-1 & $1 \mathrm{~A}$ \\
\hline 2 & Pro $^{-}$ & IB-2 & IB \\
\hline 3 & $\mathrm{Pro}^{-}$ & IB-3 & $1 \mathrm{C}, 3 \mathrm{~A}$ \\
\hline 4 & $\mathrm{Pro}^{-}$ & IB-4 & $1 \mathrm{D}$ \\
\hline 5 & $\mathrm{Pro}^{-}$ & IB-5 & $1 E$ \\
\hline $6^{*}$ & Pro $^{-}$ & IB-6 & $1 F$ \\
\hline 7 & Pro $^{-}$ & IB-7 & $1 G$ \\
\hline 8 & $\mathrm{Pro}^{-}$ & IB-2 & 2A-2I \\
\hline 9 & Pro $^{-}$ & IB-3 & $3 B$ \\
\hline 10 & Proto & IB-3 & $3 \mathrm{C}$ \\
\hline 11 & Proto & IB-3 & $3 \mathrm{D}$ \\
\hline 12 & Proto & IB-3 & $3 E$ \\
\hline $13^{*}$ & Proto & IB-3 & $3 F$ \\
\hline 14 & Proto & IB-3 & $3 G$ \\
\hline 15 & Proto & IB-3 & $3 \mathrm{H}$ \\
\hline 16 & $\mathrm{Pro}^{-}$ & IB-19 & $4 A$ \\
\hline $17^{*}$ & Pro $^{-}$ & IB-19 & 4B \\
\hline 18 & Pro $^{-}$ & IB-19 & $4 C$ \\
\hline $19^{*}$ & $\mathrm{Pro}^{-}$ & IB-19 & 4D \\
\hline $20+$ & Proto & IB-19 & $4 \mathrm{E}$ \\
\hline 21 & Proto & IB-19 & $4 \mathrm{~F}$ \\
\hline 22 & $\mathrm{Pro}^{-}$ & IB-7 & - \\
\hline $23^{*}$ & Pro $^{-}$ & IB-2 & - \\
\hline $24 \dagger$ & Proto & IB-4 & - \\
\hline 25 & Proto & IB-1 & - \\
\hline 26 & Pro $^{-}$ & IB-4 & - \\
\hline 27 & Pro $^{-}$ & IB-14 & - \\
\hline 28 & Pro $^{-}$ & IB-6 & - \\
\hline $29^{*}$ & $\mathrm{Pro}^{-}$ & IB-6 & - \\
\hline 30 & Pro $^{-}$ & IB-7 & - \\
\hline 31 & Proto & IB-7 & - \\
\hline 32 & $\mathrm{Pro}^{-}$ & IB-1 & - \\
\hline 33 & $\mathrm{Pro}^{-}$ & IB-7 & - \\
\hline $34^{*}$ & $\mathrm{Pro}^{-}$ & IB-7 & - \\
\hline $35 \dagger$ & Pro $^{-}$ & IB-6 & - \\
\hline 36 & Proto & IB-6 & - \\
\hline 37 & Pro $^{-}$ & IB-7 & - \\
\hline 38 & Pro $^{-}$ & IB-7 & - \\
\hline 39 & Pro $^{-}$ & IB-2 & - \\
\hline $40^{*}$ & Pro $^{-}$ & IB-9 & - \\
\hline 41 & Pro $^{-}$ & IB-2 & - \\
\hline 42 & $\mathrm{Pro}^{-}$ & IA-8 & - \\
\hline 43 & Proto & IB-7 & - \\
\hline 44 & $\mathrm{Pro}^{-}$ & IB-6 & - \\
\hline 45 & Proto & IB-1 & - \\
\hline 46 & Pro $^{-}$ & IB-1 & - \\
\hline 47 & Proto & IB-7 & - \\
\hline $48 \dagger$ & Proto & IB-2 & - \\
\hline
\end{tabular}

No superscripts indicate absence of plasmids.

Proto, prototrophic, wild-type.

$\mathrm{Pro}^{-}$, a requirement for proline.

* Presence of 7.2-kb plasmid.

$\dagger$ Presence of $7 \cdot 2-\mathrm{kb}$ and $39 \cdot 2-\mathrm{kb}$ plasmids.

$1 \%$ at $42^{\circ} \mathrm{C}$, distributed into the slots of a mold (BioRad Laboratories), and allowed to solidify. The agarose plugs were transferred into $10 \mathrm{ml}$ of EC lysis solution $(6 \mathrm{~mm}$ Tris- $\mathrm{HCl}, 100 \mathrm{~mm}$ EDTA, $1 \mathrm{M} \mathrm{NaCl}$, brij-58 $0.5 \%$, sodium deoxycholate $0 \cdot 2 \%$, sodium lauroyl sarcosine $0.5 \%, 10 \mathrm{mg}$ of lysozyme and 10 units of RNAase) and incubated overnight at $37^{\circ} \mathrm{C}$ with gentle shaking. After further incubation in ESP solution (0.5 M EDTA, pH 9-9.5; sodium lauroyl sarcosine $1 \%$, proteinase $\mathrm{K} 500 \mu \mathrm{g} / \mathrm{ml}$ ) for 2 days at $55^{\circ} \mathrm{C}$ with gentle shaking, the plugs were washed three times with $15 \mathrm{ml}$ of TE buffer $(10 \mathrm{~mm}$ Tris- $\mathrm{HCl}$, $\mathrm{pH} 7 \cdot 5,0 \cdot 1 \mathrm{~mm}$ EDTA) for $30 \mathrm{~min}$ and stored at $4^{\circ} \mathrm{C}$.

\section{Restriction endonuclease $D N A$ digestion}

Prepared plugs were equilibrated in $10 \mathrm{~mm}$ Tris- $\mathrm{HCl}$ for $15 \mathrm{~min}$ on ice and digested overnight at $37^{\circ} \mathrm{C}$ in $150 \mu \mathrm{l}$ of restriction buffer containing $10 \mathrm{U}$ of endonuclease (New England Biolabs, USA).

\section{Pulsed-field gel electrophoresis}

Digested plugs were sealed into slots in an agarose (SeaKem GTG agarose, FMC Corp.) $1 \%$ gel and electrophoresed in a contour-clamped homogeneous electric field (CHEF) apparatus with a hexagonal electrode array (BioRad) for $20 \mathrm{~h}$ at $200 \mathrm{~V}$ with pulse times of 5-15 s. Gels were stained with ethidium bromide solution $(1 \mu \mathrm{g} / \mathrm{ml})$ for $60 \mathrm{~min}$ and then destained in distilled water for $30 \mathrm{~min}$ before being photographed under UV transillumination. Rhodobacter sphaeroides 2.4.1 genomic DNA digested by Ase 1 was used as the mol. wt standard. ${ }^{14}$

\section{Results}

\section{Selection of restriction endonuclease}

Genomic DNA from $N$. gonorrhoeae strains was digested with the low-frequency cleavage (LFC) enzymes NotI, SfiI and $P a c I$ that recognise 8-bp sequences and NheI, SpeI and $X b a I$ that recognise 6bp sequences containing the tetranucleotide CTAG, an infrequent sequence in most bacterial genomes. ${ }^{15}$ NotI and SfiI failed to digest gonococcal DNA, presumably due to extensive DNA methylation. PacI produced suitable REA patterns but was too costly for routine use. SpeI and NheI produced suitable REA patterns, generating $12-17$ and 14-16 fragments, respectively. Sufficient strain differences were observed for the development of a typing system based on restriction fragment length polymorphisms.

\section{Typing of N. gonorrhoeae strains by SpeI and NheI digestion}

Seven proline-requiring (Pro ${ }^{-}$) strains of differing serotype were examined. All showed distinct SpeI (fig. 1) and NheI REA patterns (data not shown).

The reproducibility of PFGE REA patterns generated by both SpeI and NheI was examined by analysis of the same bacterial strain on separate occasions. Identical patterns were observed for two repeat analyses (data not shown). Mobility of the DNA fragments can vary between analyses but the presence of standard DNA mol. wt markers on each gel enabled strict comparisons to be made between separate gels. Stability of the REA pattern was also observed when the same strain (strain 8, Pro-/IB-2) was subjected to nine in-vitro passages on MTM plates (fig. 2).

\section{Comparison of PFGE analysis with $A / S$ classification}

Six strains of identical A/S (Prototrophic/IB-3) patterns were examined by PFGE analysis after NheI 


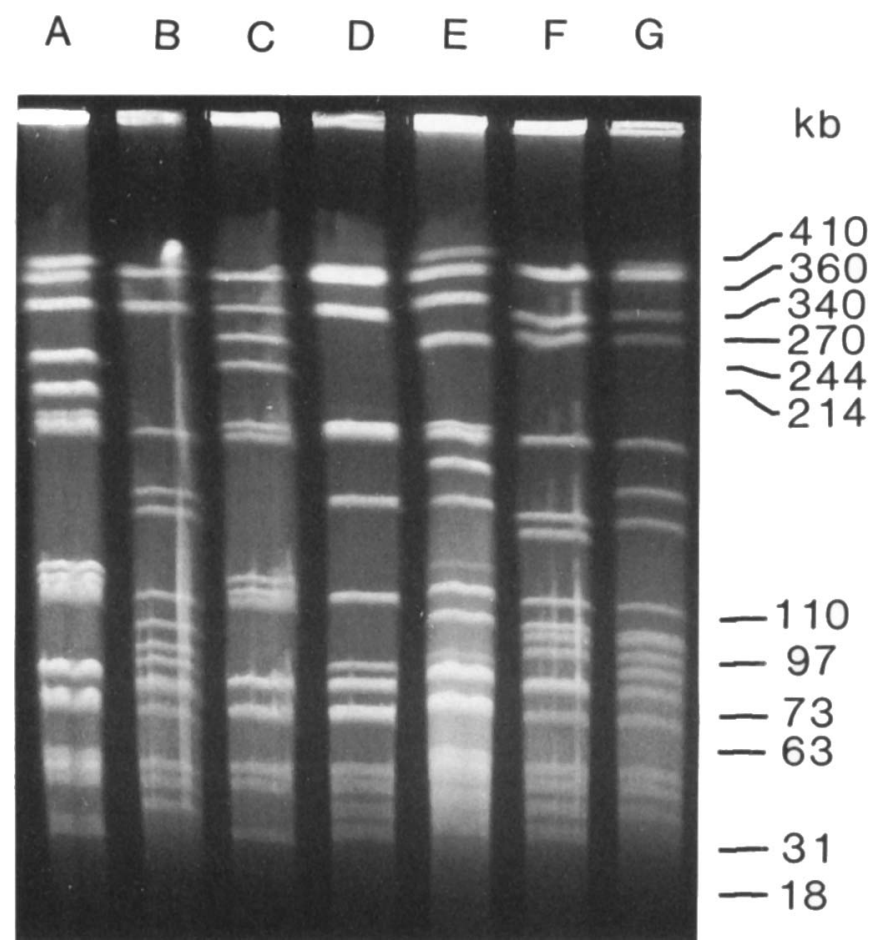

Fig. 1. Spel REA patterns of genomic DNA from $N$. gonorrhoeae Pro- auxotrophs with different serovar designations. Lane A: strain 1 (IB-1); B: strain 2 (IB-2); C: strain 3 (IB-3); D: strain 4 (IB-4); E: strain 5 (IB-5); F: strain 6 (IB-6); G: strain 7 (IB-7).

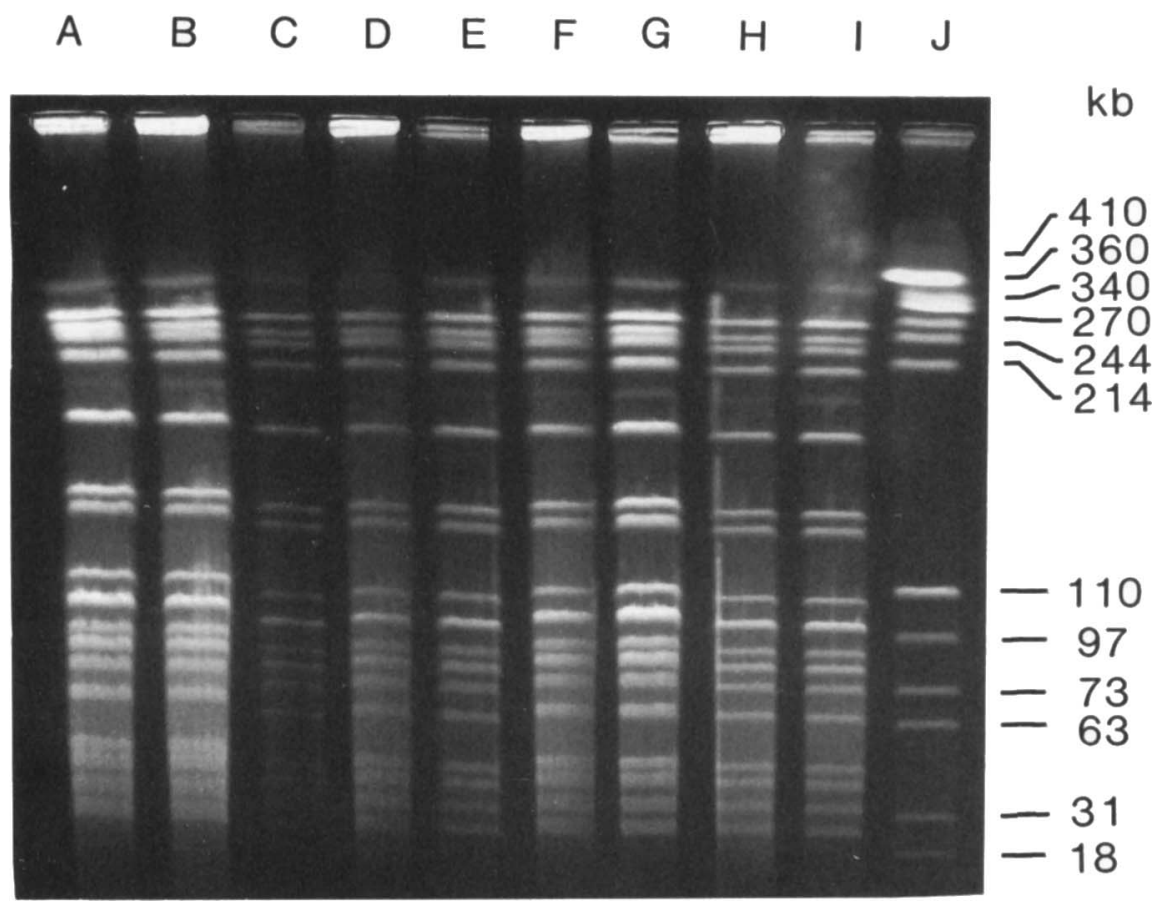

Fig. 2. Stability of SpeI PFGE profiles of $N$. gonorrhoeae strain 8 (Pro-/IB-2) after serial passages (lanes A-I). Lane J: mol.wt marker (R. sphaeroides 2.4.1 digested with Asel).

digestion (fig. 3, lanes $\mathrm{C}-\mathrm{H}$ ). Two yielded identical patterns (lanes $C$ and $D$ ), another was closely similar (lane E); the remaining isolates (lanes $\mathrm{F}, \mathrm{G}$ and $\mathrm{H}$ ) gave patterns distinct from each other and from this group. Two Pro ${ }^{-} /$IB-3 strains (lanes A and B) showed clearly distinct PFGE profiles. Thus, the eight IB-3 isolates were represented by two auxotypes but seven NheI PFGE REA patients. Of the six Prototrophic (Proto)IB-3 strains studied, two were from the same female patient and the PFGE profiles for these were identical (lanes C and D). A closely related PFGE profile was found in strain 12 (lane E) which was isolated from a different patient. The three Proto/IB3 strains exhibiting distinct PFGE profiles (lanes F, G and $\mathrm{H}$ ) were collected from three separate individuals. Based on A/S classification, the five patients would appear to be infected with a common strain (Proto/IB3) but subtyping by PFGE profiles showed that at least four strains were involved.

Similarly, six IB-19 strains of two auxotypes gave 


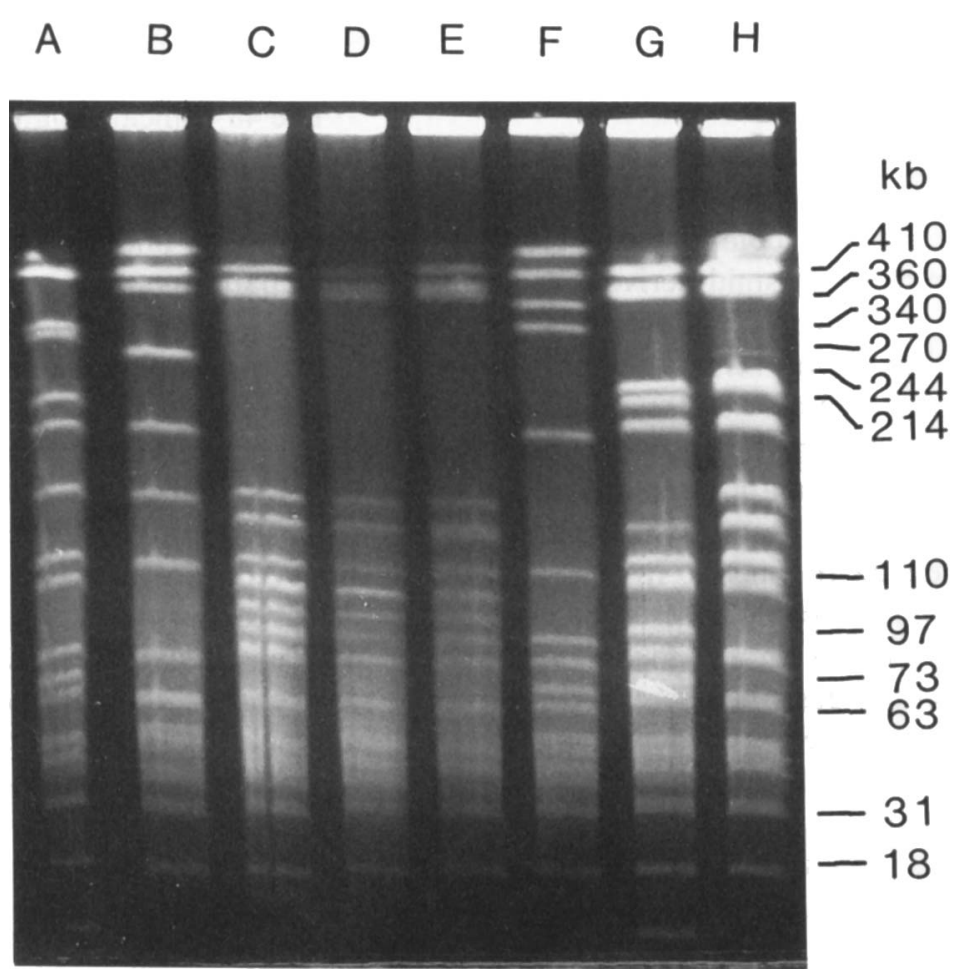

Fig. 3. NheI digestion of DNA of $N$. gonorrhoeae Pro $^{-} / \mathrm{IB}-3$ and Proto/IB-3 strains. Lane A: $\operatorname{strain} 3$ (Pro $\left.{ }^{-} / \mathrm{IB}^{-3}\right)$; B: strain 9 (Pro $\left.{ }^{-} / \mathrm{IB}^{-3}\right)$; C: strain 10 (Proto/IB-3); D: strain 11 (Proto/IB-3); E: strain 12 (Proto/IB-3); F: strain 13 (Proto/IB-3); G: strain 14 (Proto/IB-3); H: strain 15 (Proto/IB-3).

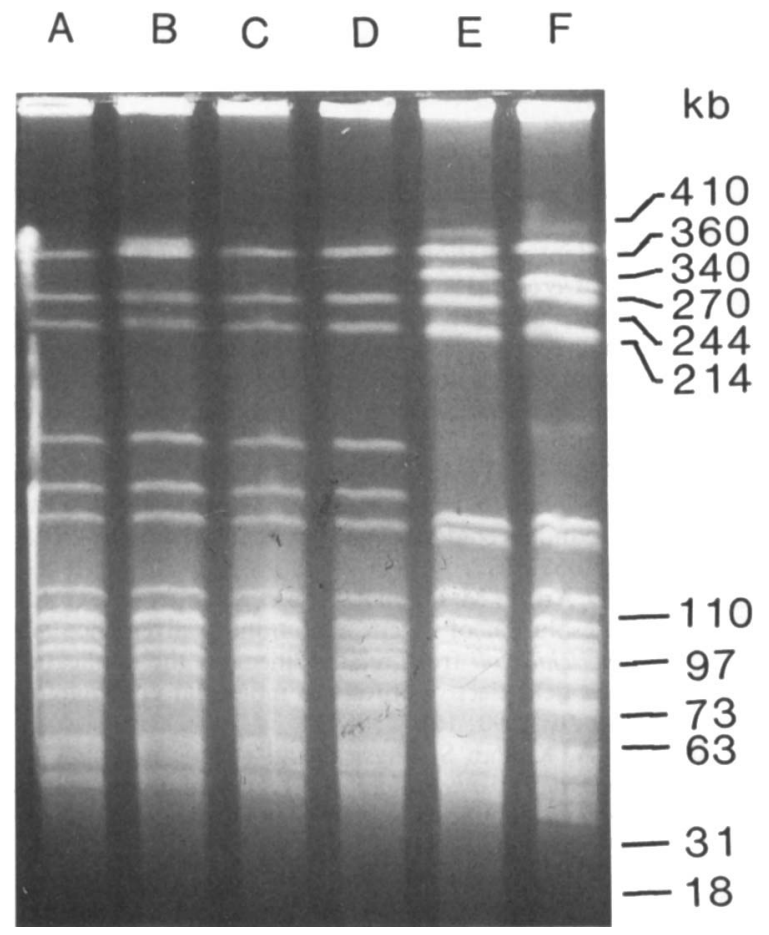

Fig. 4. SpeI digestion of DNA from N. gonorrhoeae Pro-/IB-19 and Proto/IB-19 strains. Lane A: strain 16 (Pro-/IB-19); B: strain 17 (Pro-/IB-19); C: strain 18 (Pro-/IB-19); D: strain 19 (Pro-/IB-19) E: strain 20 (Proto/IB-19); F: strain 21 (Proto/IB-19).

four SpeI PFGE profiles (fig. 4). With the exception of one strain (lane B), three $\mathrm{Pro}^{-} / \mathrm{IB}-19$ strains (lanes A, $\mathrm{C}$ and D) displayed identical SpeI PFGE profiles. Two Proto/IB-19 strains were found to exhibit different SpeI PFGE profiles (lanes E and F). The identical
PFGE profiles observed in lanes A, C and D were generated by strains 16,18 and 19 , respectively, from three separate patients, and suggest a common source of infection.

\section{Discussion}

REA has been used extensively in the typing of diverse species of bacteria. ${ }^{16}$ Usually, this has relied upon electrophoresis patterns of the low-mol.-wt fragments produced by high-frequency cleavage (HFC) enzymes. Conventional agarose or polyacrylamide gel electrophoresis of low-mol.-wt fragments tend to generate complex REA patterns that are difficult to interpret. High-mol.-wt DNA fragments with no known cleavage sites for the particular restriction endonuclease chosen could not be resolved. Falk's study ${ }^{6}$ on REA pattern analysis relied mainly on HindIII digestion that generates fragments of $<5 \mathrm{~kb}$ in polyacrylamide gel electrophoresis. Agarose electrophoresis ${ }^{7}$ provided excellent resolution of fragments from 2 to $6.5 \mathrm{~kb}$ for HinfI-digested DNA and from 2.5 to $21.5 \mathrm{~kb}$ for $B g h I$-digested DNA. When REA patterns differed in these size ranges, their nonidentity was clear, but strains sharing indistinguishable low-mol.-wt patterns might still differ in sequence in areas of the genome represented by the unresolved, high-mol.-wt DNA fragments in these digests. Falk et al. ${ }^{17}$ compared REA with A/S classification and found REA to be more discriminatory. Correlations were seen between some REA patterns and auxotypes. 
However, they concluded that the choice and number of restriction endonucleases could influence the sensitivity of REA.

Fingerprinting by $\mathrm{CHEF}$ analysis provides a method for comparison of the whole genome including chromosome and plasmid components. However, resolution of plasmids or plasmid-derived fragments depends upon the presence of endonuclease target sequences and the sizes of the plasmids and fragments. Small plasmids and low-mol.-wt plasmid fragments can be resolved under certain PFGE conditions. When chromosomal PFGE patterns appeared identical, conditions could be chosen for resolution of small plasmids or plasmid-derived fragments. In this way, the whole genome of any strain could be screened. Another advantage is the cost saving on media and subculturing. In the method described here, growth from a single plate is used, whereas that of Falk et al. ${ }^{6}$ required growth from up to six plates. The cost of PFGE analysis is largely dependent upon the restriction endonucleases used. Although SpeI and NheI were equally discriminatory, the latter is preferred as it costs substantially less.

Reproducibility and stability of the REA patterns was confirmed by the identical fingerprints obtained from a single strain resolved in different gels and the stability of REA patterns over nine repeated subcultures. Recombination and chromosomal rearrangements at reiterated sequence ${ }^{18}$ sites might

\section{References}

1. Sandström EG, Rudén A-K. Markers of Neisseria gonorrhoeae for epidemiological studies. Scand J Infect Dis 1990; Suppl. 69: 149-156.

2. Knapp JS. Laboratory methods for the detection and phenotypic characterization of Neisseria gonorrhoeae strains resistant to antimicrobial agents. Sex Transm Dis 1988; 15 : 225-233.

3. Sarafan SK, Knapp JS. Molecular epidemiology of gonorrhea. Clin Microbiol Rev 1989; 2 Suppl: S49-S55.

4. Knapp JS, Tam MR, Nowinski RC, Holmes KK, Sandström EG. Serological classification of Neisseria gonorrhoeae with use of monoclonal antibodies to gonococcal outer membrane protein I. J Infect Dis 1984; 150: 44-48.

5. Gill MJ. Serotyping Neisseria gonorrhoeae: a report of the fourth international workshop. Genitourin Med 1991; 67: 53-57.

6. Falk ES, Bjorvatn B, Danielsson D, Kristiansen BE, Melby K, Sørensen B. Restriction endonuclease fingerprinting of chromosomal DNA of Neisseria gonorrhoeae. APMIS 1984; 92 : $271-278$.

7. Poh CL, Ocampo JC, Sng EH, Bygdeman SM. Rapid in situ generation of DNA restriction endonuclease patterns for Neisseria gonorrhoeae. J Clin Micribiol 1989; 27: 2784 2788.

8. Smith CL, Kico SR, Cantor CR. Pulsed-field gel electrophoresis and the technology of large DNA molecules. In: Davies KE (ed) Genome analysis: a practical approach. Oxford, IRL Press. 1988: 41-72.

9. Vazquez JA, Beckley A, Sobel JD, Zervos MJ. Comparison of restriction enzyme analysis and pulsed-field gradient gel electrophoresis as typing systems for Candida albicans. $J$ Clin Microbiol 1991; 29: 962-967.

10. Allardet-Servent A, Bouziges N, Carles-Nurit MJ, Bourg G, change the restriction pattern but this was not observed during the present study.

The 48 clinical isolates studied were represented by two auxotypes and 11 different serovars. Combination of auxotyping and serotyping produced $18 \mathrm{~A} / \mathrm{S}$ classes. The findings of $38 \mathrm{SpeI}$ and $40 \mathrm{NheI}$ CHEF REA patterns amongst the group of 48 isolates studied clearly demonstrated that PFGE was more discriminatory than either auxotyping or MAb-based serotyping. Strains were clearly differentiated and a positive correlation was observed in some strains between PFGE patterns and A/S patterns. Discrimination of strains within major serovars IB-1 and IB-3 was achieved. Serovar classes IB-5 and IB-7, which differ in their reaction with a single antibody, could also be differentiated and PFGE is clearly the method of choice for differentiation of strains that are $\mathrm{A} / \mathrm{S}$ untypable. Clearly, a larger study, involving analysis of isolates from cohorts and covering a broad range of auxotypes and serovars is required, but the method shows considerable promise as a highly discriminatory tool for the epidemiological investigation of gonorrhoea.

We thank J. E. H. Sng for the strains, and S. Sarafian and Joan Knapp, Centers for Disease Control, Atlanta, GA, for their A/S typing data on these strains. We are also grateful to $\mathrm{A}$. Suwanto and S. Kaplan, University of Texas Medical School, Houston, for introducing one of us (C. L.P.) to PFGE and the many fruitful hours of discussion which made this study possible. This study was supported by NUS research grant RP 3910459.

Gouby A, Ramuz M. Use of low-frequency-cleavage restriction endonucleases for DNA analysis in epidemiological investigations of nosocomial bacterial infections. $J$ Clin Microbiol 1989; 27 : 2057-2061.

11. Prevost G, Pottecher B, Dahlet M, Bientz M, Mantz JM, Piémont Y. Pulsed field gel electrophoresis as a new epidemiological tool for monitoring methicillin-resistant Staphylococcus aureus in an intensive care unit. J Hosp Infect 1991; 17: 255-269.

12. Yan W, Chang N, Taylor DE. Pulsed-field gel electrophoresis of Campylobacter jejuni and Campylobacter coli genomic DNA and its epidemiologic application. J Infect Dis 1991; 163: 1068-1072

13. Arbeit RD, Arthur M, Dunn R, Kim C, Selander RK, Goldstein $\mathbf{R}$. Resolution of recent evolutionary divergence among Escherichia coli from related lineages: the application of pulsed field electrophoresis to molecular epidemiology. $J$ Infect Dis 1990; 161: 230-235.

14. Suwanto A, Kaplan S. Physical and genetic mapping of the Rhodobacter sphaeroides 2.4.1. genome: genome size, fragment identification, and gene localization. J Bacteriol 1989 ; 171 : $5840-5849$.

15. McClelland $\mathbf{M}$, Jones $\mathbf{R}$, Patel $\mathbf{Y}$, Nelson $\mathbf{M}$. Restriction endonucleases for pulsed field mapping of bacterial genomes. Nucleic Acids Res 1987; 15: 5985-6005.

16. Eisenstein BI, Englesberg NC. Applied molecular genetics: new tools for microbiologists and clinicians. J Infect Dis 1986; 153: $416-430$.

17. Falk ES, Egglestone SI, Digranes A, Volden G, Bjorvatn B. Genotypic and phenotypic markers in the differentiation of Neisseria gonorrhoeae strains. APMIS 1988; 109-116.

18. Dempsey JAF, Litaker W, Madhure A, Snodgrass TL, Cannon JG. Physical map of the chromosome of Neisseria gonorrhoeae FA 1090 with locations of genetic markers, including opa and pil genes. $J$ Bacteriol 1991; 173: 5476 5486 . 